Article

\title{
Respiratory and Cardiovascular Parameters Evaluation in OSA Patients Treated with Mandibular Advancement Device
}

\author{
Ciavarella Domenico ${ }^{1}$, Tepedino Michele ${ }^{1,2, * \mathbb{D}}$, Burlon Giuseppe $^{1}$, Ferrara Donatella ${ }^{1}$, \\ Cazzolla Angela Pia ${ }^{1}$, Laurenziello Michele ${ }^{1}$, Illuzzi Gaetano ${ }^{1}{ }^{\mathbb{D}}$, Suriano Carmela ${ }^{1}$ and \\ Cassano Michele ${ }^{1}$ \\ 1 Department of Clinical and Experimental Medicine, University of Foggia, 71122 Foggia, Italy; \\ domenico.ciavarella@unifg.it (C.D.); giuseppeburlon@gmail.com (B.G.); donatella.ferrara@unifg.it (F.D.); \\ angelapia.cazzolla@unifg.it (C.A.P.); michele.laurenziello@unifg.it (L.M.); gaetano.illuzzi@unifg.it (I.G.); \\ carmela.suriano@unifg.it (S.C.); michele.cassano@unifg.it (C.M.) \\ 2 Department of Biotechnological and Applied Clinical Sciences, University of L'Aquila, 67100 L'Aquila, Italy \\ * Correspondence: michele.tepedino@univaq.it; Tel.: +39-0862-434782
}

Received: 29 September 2020; Accepted: 16 November 2020; Published: 18 November 2020

\begin{abstract}
Obstructive sleep apnea (OSA) is associated with a number of cardiovascular comorbidities, including hypertension, heart rate (HR) alterations, cardiac arrhythmias, endothelial dysfunction and atherosclerosis. HR, in particular, is an important sign correlated with cardiac stress and survival. Previous investigations on the effects of mandibular advancement device (MAD) therapy on HR resulted in contradictory findings. The aim of the present retrospective cohort study was to evaluate the effects of MAD therapy with a fully customizable appliance on respiratory and cardiovascular parameters. Fifty adult consecutive cases with mild to severe OSA underwent split-night polysomnography (SN-PSG) at baseline (T0) and after three months of MAD treatment (T1), after appropriate titration. The apnea/hypopnea index (AHI), $4 \%$ oxygen desaturation index (ODI) and HR (average, minimum and maximum) values are recorded at T0 and at T1 and statistically compared. The AHI and ODI values improved after three months of MAD treatment. The minimum HR increased after treatment, while the maximum HR decreased after treatment. MAD treatment with a fully customizable appliance was effective in improving breathing and cardiovascular parameters in adult patients with mild to severe OSA.
\end{abstract}

Keywords: obstructive sleep apnea; OSA; heart rate; mandibular advancement device

\section{Introduction}

Obstructive sleep apnea (OSA) in adults is a condition with a high public health impact [1]. OSA is characterized by recurring episodes of cessation (apnea) or reduction (hypopnea) in airflow during sleep caused by obstruction of the upper airway [2]. OSA affects $4 \%$ to $6 \%$ of middle-aged men and $2 \%$ to $4 \%$ of middle-aged women and its frequency increases with age [3]. People at higher risk of developing OSA include those with enlarged tonsils and/or adenoids, a family history of OSA, excessive weight/obesity, actively smoking and jaw problems, such as micrognathia or retrognathia [4].

The sleep arousal caused by OSA induces excessive daytime sleepiness (EDS) [5], increases the occurrence of driving accidents [6], induces reductions in concentration in both adults and children [7] and induces sleep fragmentation, which in some cases may induce depression [8]. Moreover, the intermittent hypoxia caused by the apnea/hypopnea events initiates a sequence of systemic alterations, including activation of the sympathetic nervous system, systemic inflammation, oxidative stress, endothelial dysfunction and atherosclerosis [9-12]. As a consequence, OSA seems to 
determine cardiovascular comorbidities, such as alterations in heart rate (HR), systemic hypertension, myocardial infarction, cardiac arrhythmias and stroke [13-15]. HR variability, in particular, is a clinical sign measured easily and non-invasively but it has been demonstrated to be directly associated with survival (higher HR indicates lower survival) in the general population and in patients with impaired cardiovascular function [16,17]. In fact, an increase in HR by 10 beats per minute has been associated with a $20 \%$ increase in the risk of cardiac death, which is comparable to the increased risk correlated to an increase of systolic blood pressure by $10 \mathrm{~mm} \mathrm{Hg} \mathrm{[18].}$

To reduce the number of apnea/hypopnea events and contrast the onset of other comorbidities, continuous positive airway pressure (CPAP) is the most common treatment of patients with OSA [19]. Other suggested treatments are surgery [20] or the use of a mandibular advancement device (MAD) [21]. In 1995, The American Academy of Sleep Medicine (AASM) stated that a MAD was indicated as a first-line therapy for mild OSA and a second-line therapy for moderate to severe OSA [22]. However, the studies that investigated the effectiveness of MAD therapy in improving cardiovascular parameters compared to CPAP reported contradictory findings [23,24].

Therefore, the aim of the present retrospective cohort study was to evaluate the effects of MAD therapy with a particular fully customizable appliance on respiratory and cardiovascular parameters in an adult population with OSA.

\section{Materials and Methods}

The sample size calculation ( $G *$ Power version 3.1.9.2, Franz Faul, Universität Kiel, Germany) revealed that to be able to detect a moderate effect size of 0.5 with a probability of 0.05 and a power of $0.9,44$ subjects were needed. Therefore, 50 consecutive subjects ( 26 men and 24 women; mean age of $48.5 \pm 8.7$ years) with a diagnosis of OSA were retrospectively enrolled in the present study among the patients treated at the Department of Orthodontics, University of Foggia, Italy, in chronological order from January 2016 to February 2019. To be included in the study, the patients had to fulfil the following inclusion criteria: age greater than 20 years old, body mass index (BMI) lower than $34 \mathrm{~kg} / \mathrm{m}^{2}$, OSA diagnosis confirmed by nocturnal polysomnography, treatment with night-time MAD therapy using a fully customizable device after a drug-induced sleep endoscopy (DISE) and completeness of diagnostic records. Exclusion criteria were a smoking habit, the presence of comorbidities like cardiovascular or pulmonary diseases at the moment of the OSA diagnosis, taking concomitant medications for neurological disorders or a history of cervical head trauma.

All the procedures described in the present research protocol adhered to the Declaration of Helsinki (1975) (and the subsequent revisions) and were approved by the Ethical Committee of the University of Foggia (Approval no. 43/CE/2019) and all patients gave their informed consent to participate.

MAD treatment was always initiated after performing a DISE. Every patient, before MAD treatment (T0), received split-night polysomnography (SN-PSG) with at least $4 \mathrm{~h}$ of continuous recording in a sleep laboratory using a type 2 portable device (Embletta system X-100, Flaga, Reykjavik, Iceland) after one night of adaptation to the hospital setting. The SN-PSG recording comprehended electroencephalograms, electro-oculograms, electromyograms, pulse oximetry channels, abdominal respiratory effort bands, body position sensors, nasal cannulas and oral thermistor. The first $3 \mathrm{~h}$ of recording, as recommended by several authors [25-28], were used for manual scoring according to the AASM criteria from 2007 [29].

The following parameters were recorded and stored for further analysis: apnea/hypopnea index (AHI); oxygen desaturation index (ODI), which corresponds to the number of desaturation events higher than $4 \%$ of the baseline value per hour of sleep; and the average HR, minimum HR and maximum HR.

A second SN-PSG was performed after 3 months of treatment (T1) with a fully customizable MAD (Protrusor ${ }^{\circledR}$, nonrusso $+{ }^{\circledR}$, Dr Giuseppe Burlon, Belluno, Italy). The MAD (Figure 1) was made of two resin splints joined by two threaded titanium bars with two titanium screws each, which represents the protrusive mechanism. The head of the titanium screws allows for lateral excursion of the mandible for 
improved patient comfort. The amount of mandibular advancement was determined for each patient after a titration period. Initially, an intraoral gauge (Occlusion ${ }^{\circledR}$, nonrusso $+{ }^{\circledR}$, Dr Giuseppe Burlon, Belluno, Italy) was used to set the advancement at $70 \%$ of the total possible mandibular advancement; then, during follow-up appointments, usually every 15 days, the therapeutic mandibular protrusion was adjusted by $1 \mathrm{~mm}$ or $2 \mathrm{~mm}$ increments until reaching the most comfortable position that allowed relief from the symptoms, as described in a previous study [30].

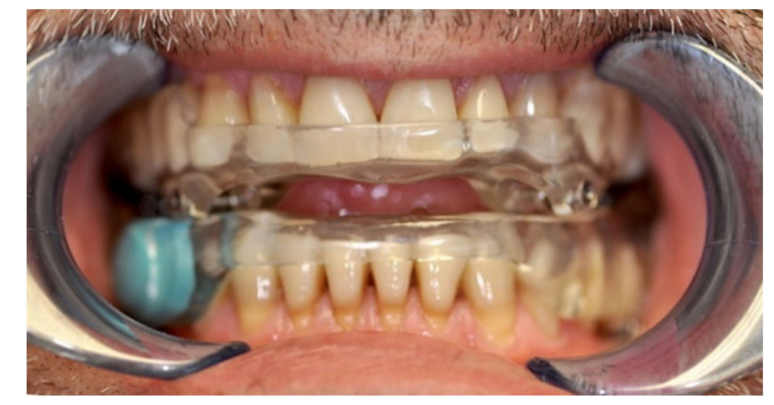

Figure 1. Intraoral view of the customizable mandibular advancement device.

\section{Statistical Analysis}

Descriptive statistics were calculated for all the variables. The assumption of a normal distribution of data was tested with the Kolmogorov-Smirnov test and probability plots. To evaluate the presence of a statistically significant difference between the pre- and post-treatment values of AHI, ODI, average $\mathrm{HR}$, minimum HR and maximum HR, a paired samples $t$-test or a Wilcoxon signed ranked test was performed, according to the type of data distribution. First-type error was set as $p<0.05$. All statistical analyses were performed using GraphPad Prism software 6.0 (San Diego, CA, USA).

\section{Results}

Descriptive statistics are reported in Table 1. Due to the non-normal distribution of most of the variables, a non-parametric test was used for all the comparisons except for the minimum HR. The present data show how, using a MAD device, respiratory parameters have been significantly reduced, decreasing apnea/hypopnea and desaturation events considerably. In fact, the mean AHI decreased by 21 and the ODI decreased by 13.8 .

Table 1. Descriptive statistics for the studied variables and statistical comparison before and after mandibular advancement device (MAD) therapy $(n=50)$.

\begin{tabular}{|c|c|c|c|c|c|c|c|}
\hline \multicolumn{2}{|c|}{ Variable } & \multirow{3}{*}{$\begin{array}{c}\text { Mean } \\
25.34 \\
5.53\end{array}$} & \multirow{3}{*}{$\begin{array}{c}\begin{array}{c}\text { Standard } \\
\text { Deviation }\end{array} \\
10.6 \\
4.1\end{array}$} & \multirow{3}{*}{$\begin{array}{c}\begin{array}{c}\text { Mean } \\
\text { Difference }\end{array} \\
-21.25\end{array}$} & \multirow{3}{*}{$\begin{array}{c}\text { Normality } \\
\text { Test } \\
* \\
*\end{array}$} & \multirow{3}{*}{$\begin{array}{c}\text { Test } \\
\text { Wilcoxon } \\
\text { signed rank }\end{array}$} & \multirow{3}{*}{$\begin{array}{c}p \text { Value } \\
* *\end{array}$} \\
\hline & T0 & & & & & & \\
\hline AHI & $\mathrm{T} 1$ & & & & & & \\
\hline \multirow{2}{*}{ ODI } & T0 & 17.71 & 8.1 & \multirow[b]{2}{*}{-13.87} & ns & \multirow{2}{*}{$\begin{array}{l}\text { Wilcoxon } \\
\text { signed rank }\end{array}$} & \multirow[b]{2}{*}{$* *$} \\
\hline & $\mathrm{T} 1$ & 3.84 & 3.0 & & * & & \\
\hline \multirow{2}{*}{ Mean HR } & T0 & 59.92 & 7.1 & \multirow{2}{*}{-2.12} & * & \multirow{2}{*}{$\begin{array}{l}\text { Wilcoxon } \\
\text { signed rank }\end{array}$} & \multirow[b]{2}{*}{ ns } \\
\hline & $\mathrm{T} 1$ & 57.80 & 6.9 & & ns & & \\
\hline \multirow{2}{*}{$\mathrm{HR} \min$} & T0 & 42.25 & 10.0 & \multirow{2}{*}{+4.29} & ns & \multirow{2}{*}{$\begin{array}{c}\text { Paired samples } \\
\text { T test }\end{array}$} & \multirow{2}{*}{ * } \\
\hline & $\mathrm{T} 1$ & 46.54 & 8.1 & & ns & & \\
\hline \multirow{2}{*}{ HR max } & T0 & 136.10 & 44.6 & \multirow{2}{*}{-20.4} & $*$ & \multirow{2}{*}{$\begin{array}{l}\text { Wilcoxon } \\
\text { signed rank }\end{array}$} & \multirow[b]{2}{*}{ * } \\
\hline & $\mathrm{T} 1$ & 115.70 & 34.8 & & ns & & \\
\hline
\end{tabular}

* Statistically significant with $p<0.05 ;{ }^{* *}$ statistically significant with $p<0.01$; ns, non-significant. Mandibular advancement device (MAD), apnea/hypopnea index (AHI), oxygen desaturation index (ODI), heart rate (HR) in beats per minute. 
Heart parameters are also significantly modified as a result of the use of a MAD. In particular, the maximum HR value decreased by $20 \mathrm{bpm}$ and the minimum HR value increased by $4 \mathrm{bpm}$ after MAD therapy. On the other hand, the value of the mean HR decreased by -2.12 , which was statistically insignificant.

\section{Discussion}

Generally, a sleep disorder causes a worsening of life quality and increases morbidity and mortality in a large part of patients. In particular, patients with OSA often have comorbid conditions, which can contribute to the onset of more serious clinical situations. Several studies have reported the presence of common comorbidities with OSA, such as cardiovascular disease (CVD), cognitive impairment, psychiatric problems (including depression), diabetes and obesity, although the etiopathogenesis pathway is not completely understood, therefore it is not clear if a condition is a consequence of OSA or a risk factor [31]. It was also demonstrated that OSA can predispose patients to an augmented prevalence of hypertension, heart failure, arrhythmias and mortality. This relationship involves not only the early onset of cardiovascular and metabolic diseases but also their progression. Obstructed breathing causes negative intrathoracic pressure in association with hypoxia and hypercapnia. Hypoxemic stress is further amplified by subsequent reoxygenation (intermittent hypoxia), which leads to a production of reactive oxygen species (ROS), activation of the sympathetic system and inflammation. Every time that an apnea occurs, hypoxia-hypercapnia followed by reoxygenation also alter the exchange of physiological blood gases. When chemoreflex activation occurs, electroencephalography alterations (microarousals) are also evident; each inspiratory effort against the occluded upper airways induces an increase in negative intrathoracic pressure leaving significant consequences on the heart's anatomy, such as atrial enlargement and remodeling and stretching of the ostia of the pulmonary vein.

All these acute mechanisms of obstructive apnea will activate several biological pathways. The most relevant one being the autonomic nervous system (ANS) deregulation, with recurrent bursts of sympathetic activity elicited by the activation of chemoreflexes and by the sympathetic and parasympathetic coactivation, which occur repeatedly during the onset of apnea. This sympathetic/parasympathetic coactivation is very typical of OSA and it may represent a decisive factor in triggering major life-threatening arrhythmias in such patients. Moreover, apneic events may also activate a wide range of intermediate mechanisms, such as oxidative stress, the systemic inflammatory response, platelet activation and aggregation, endothelial dysfunction and metabolic alterations [32].

The first-line treatment of breathing-related sleep disorders may include behavioral modifications and CPAP [33]. Alternatives for patients unable to adhere to CPAP therapy include upper airway surgery [33,34] or the use of MADs [35]. In children there are also other options that are being studied, such as palatal expansion [36-38]. Studies comparing the effectiveness of CPAP and MAD therapy reported a significant decrease in the AHI compared with baseline over a two-year treatment period for both interventions, suggesting the use of oral appliances as a viable alternative to CPAP therapy in patients with mild to moderate OSA [35].

In this research, we also found a significant variation of HR values after using MAD therapy.

The average minimum HR increased, while the average maximum HR decreased. These findings are in accordance with those of previous studies. Glos et al. observed that both MAD therapy and CPAP therapy led to improvements in blood pressure and episodes of breathing cessation in patients with mild to severe OSA [39]; similarly, in a systematic review of the literature, the HR reduction after MAD therapy was concluded to be comparable to that observed after CPAP therapy [40].

Several authors have demonstrated how variations of HR can represent a risk factor for the onset of CVD. Many biological mechanisms can elucidate the relationship between high HR, atherosclerosis and cardiovascular events. Tachycardia may be the consequence of an unbalanced tone of the ANS. In addition, even though increased sympathetic activity alone could trigger a cardiovascular event in a subject with tachycardia, a direct connection between high HR and both the formation of atherosclerotic 
lesions and occurrence of cardiovascular events have also been proven [41]. Recently, the European guidelines for treating hypertension and CVD have rendered the importance of HR measurement [42].

A faster heartbeat is often linked to higher blood pressure levels and these two elements may increase the chances of cardiovascular risk. Several epidemiological studies have shown that a rise in cardiovascular risk related to the accelerated HR persists after blood pressure levels have adjusted [42]. The role of HR on cardiovascular risk is further explained by the fact that bradycardia, similarly to a higher pulse rate, may be an independent risk factor for cardiovascular events in apparently healthy men from the general population. While a higher pulse rate increased the risk of having a stroke, bradycardia tended to raise the risk of incident myocardial infarction and ischemic stroke [43]. Therefore, the HR improvement that was observed in the present study following a reduction in AHI and ODI, as a consequence of MAD treatment, is of great clinical importance for the patients and represents an additional clinical advantage for the patient.

Regarding the limitations of the present study, the retrospective design could represent a source of bias, although care was taken to follow a chronological order and strict inclusion and exclusion criteria. In addition, a longer follow-up would be useful to evaluate long-term results.

\section{Conclusions}

MAD therapy with a fully customizable appliance was effective in improving AHI, ODI and HR in an adult population with mild to severe OSA. In particular, a decrease in the maximum HR and an increase in the minimum HR were observed, suggesting a reduction in HR variability.

Author Contributions: Conceptualization, C.D.; methodology, B.G., F.D. and C.A.P.; validation, C.M.; formal analysis, C.D. and T.M.; investigation, L.M.; resources, I.G.; data curation, S.C.; writing-original draft preparation, C.D.; writing-review and editing, T.M.; and supervision, C.M. All authors have read and agreed to the published version of the manuscript.

Funding: This research received no external funding.

Conflicts of Interest: The authors have no conflicts of interest to disclose, except for Dr Giuseppe Burlon who is the owner of the patents and the registered trademarks for Occlusion ${ }^{\circledR}$, nonrusso ${ }^{\circledR}$ and Protrusor ${ }^{\circledR}$.

\section{References}

1. Walia, H.K.; Thompson, M.N.R.; Pascoe, M.; Faisal, M.; Moul, D.E.; Katzan, I.; Mehra, R.; Foldvary-Schaefer, D.N. Effect of Positive Airway Pressure Therapy on Drowsy Driving in a Large Clinic-Based Obstructive Sleep Apnea Cohort. J. Clin. Sleep Med. 2019, 15, 1613-1620. [CrossRef] [PubMed]

2. Laratta, C.R.; Ayas, N.T.; Povitz, M.; Pendharkar, S.R. Diagnosis and treatment of obstructive sleep apnea in adults. Can. Med. Assoc. J. 2017, 189, E1481-E1488. [CrossRef] [PubMed]

3. Castillo, S.G.; Vázquez, M.D.P.S.H.; Navarro, R.C.; Ruiz, J.C.; González, F.J.C.; Mayoral, R.G.; López, P.J.T.; Montes, J.A.R. Síndrome de apneas-hipopneas durante el sueño. An. Pediatría 2018, 88, 266-272. [CrossRef] [PubMed]

4. Rowley, A.J.; Lareau, S.; Fahy, B.F.; Garvey, C.; Sockrider, M. What Is Obstructive Sleep Apnea in Adults? Am. J. Respir. Crit. Care Med. 2017, 196, P1-P2. [CrossRef]

5. Isidoro, S.I.; Salvaggio, A.; Bue, A.L.; Romano, S.; Marrone, O.; Insalaco, G. Effect of obstructive sleep apnea diagnosis on health related quality of life. Health Qual. Life Outcomes 2015, 13, 1-6. [CrossRef] [PubMed]

6. Hartenbaum, N.; Collop, N.; Rosen, I.; Phillips, B. Truckers with OSA, Should They Be Driving? J. Occup. Environ. Med. 2006, 48, 871-872. [CrossRef]

7. Sateia, M.J. Neuropsychological impairment and quality of life in obstructive sleep apnea. Clin. Chest Med. 2003, 24, 249-259. [CrossRef]

8. Yosunkaya, S.; Kutlu, R.; Cihan, F.G. Evaluation of depression and quality of life in patients with obstructive sleep apnea syndrome. Niger. J. Clin. Prac. 2016, 19, 573-579. [CrossRef]

9. Drager, L.F.; Polotsky, V.Y.; Lorenzi-Filho, G. Obstructive Sleep Apnea. Chest 2011, 140, 534-542. [CrossRef]

10. Hoyos, C.M.; Melehan, K.; Liu, P.Y.; Grunstein, R.; Phillips, C.L. Does obstructive sleep apnea cause endothelial dysfunction? A critical review of the literature. Sleep Med. Rev. 2015, 20, 15-26. [CrossRef] 
11. Eisele, H.-J.; Markart, P.; Schulz, M.R. Obstructive Sleep Apnea, Oxidative Stress, and Cardiovascular Disease: Evidence from Human Studies. Oxid. Med. Cell. Longev. 2015, 2015, 608438. [CrossRef] [PubMed]

12. Nadeem, R.; Molnar, J.; Madbouly, E.M.; Nida, M.; Aggarwal, S.; Sajid, H.; Naseem, J.; Loomba, R. Serum Inflammatory Markers in Obstructive Sleep Apnea: A Meta-Analysis. J. Clin. Sleep Med. 2013, 9, 1003-1012. [CrossRef] [PubMed]

13. Al-Falahi, Z.; Williamson, J.P.; Dimitri, H. Atrial Fibrillation and Sleep Apnoea: Guilt by Association? Hear. Lung Circ. 2017, 26, 902-910. [CrossRef] [PubMed]

14. Floras, J.S. Hypertension and Sleep Apnea. Can. J. Cardiol. 2015, 31, 889-897. [CrossRef]

15. Kim, Y.S.; Kim, S.Y.; Park, D.Y.; Wu, H.W.; Hwang, G.-S.; Kim, H.-J. Clinical Implication of Heart Rate Variability in Obstructive Sleep Apnea Syndrome Patients. J. Craniofacial. Surg. 2015, 26, 1592-1595. [CrossRef]

16. Böhm, M.; Reil, J.-C.; Deedwania, P.; Kim, J.B.; Borer, J.S. Resting Heart Rate: Risk Indicator and Emerging Risk Factor in Cardiovascular Disease. Am. J. Med. 2015, 128, 219-228. [CrossRef]

17. Kannel, W.B.; Kannel, C.; Paffenbarger, R.S.; Cupples, L. Heart rate and cardiovascular mortality: The Framingham study. Am. Heart J. 1987, 113, 1489-1494. [CrossRef]

18. Benetos, A.; Rudnichi, A.; Thomas, F.; Safar, M.; Guize, L. Influence of Heart Rate on Mortality in a French Population. Hypertension 1999, 33, 44-52. [CrossRef]

19. Batool-Anwar, S.; Goodwin, J.L.; Drescher, A.A.; Baldwin, C.M.; Simon, R.D.; Smith, T.W.; Quan, S.F. Impact of CPAP on Activity Patterns and Diet in Patients with Obstructive Sleep Apnea (OSA). J. Clin. Sleep Med. 2014, 10, 465-472. [CrossRef]

20. Handler, E.; Hamans, E.; Goldberg, A.N.; Mickelson, S. Tongue suspension. Laryngoscope 2014, 124, 329-336. [CrossRef]

21. Alessandri-Bonetti, A.; Bortolotti, F.; Moreno-Hay, I.; Michelotti, A.; Cordaro, M.; Alessandri-Bonetti, G.; Okeson, J.P. Effects of mandibular advancement device for obstructive sleep apnea on temporomandibular disorders: A systematic review and meta-analysis. Sleep Med. Rev. 2019, 48, 101211. [CrossRef] [PubMed]

22. Bhat, W.M.; Jayesh, S.R. Mandibular advancement device for obstructive sleep apnea: An overview. J. Pharm. Bioallied Sci. 2015, 7, S223-S225. [CrossRef] [PubMed]

23. Andrén, A.; Hedberg, P.; Walker-Engström, M.-L.; Wahlén, P.; Tegelberg, Å. Effects of treatment with oral appliance on 24-h blood pressure in patients with obstructive sleep apnea and hypertension: A randomized clinical trial. Sleep Breath. 2012, 17, 705-712. [CrossRef]

24. Gotsopoulos, H.; Kelly, J.J.; Cistulli, P.A. Oral Appliance Therapy Reduces Blood Pressure in Obstructive Sleep Apnea: A Randomized, Controlled Trial. Sleep 2004, 27, 934-941. [CrossRef]

25. Kapur, V.K.; Auckley, D.H.; Chowdhuri, S.; Kuhlmann, D.C.; Mehra, R.; Ramar, K.; Harrod, C.G. Clinical Practice Guideline for Diagnostic Testing for Adult Obstructive Sleep Apnea: An American Academy of Sleep Medicine Clinical Practice Guideline. J. Clin. Sleep Med. 2017, 13, 479-504. [CrossRef] [PubMed]

26. Khawaja, I.S.; Olson, E.J.; Van Der Walt, C.; Bukartyk, J.; Somers, V.; Dierkhising, R.; Morgenthaler, T.I. Diagnostic Accuracy of Split-Night Polysomnograms. J. Clin. Sleep Med. 2010, 6, 357-362. [CrossRef]

27. Chou, K.-T.; Chang, Y.-T.; Chen, Y.-M.; Su, K.-C.; Perng, D.-W.; Chang, S.-C.; Shiao, G.-M. The minimum period of polysomnography required to confirm a diagnosis of severe obstructive sleep apnoea. Respirology 2011, 16, 1096-1102. [CrossRef]

28. Collop, N.A.; McDowell, A.W.; Boehlecke, B.; Claman, D.; Goldberg, R.; Gottlieb, D.J.; Hudgel, D.; Sateia, M.; Schwab, R. Clinical Guidelines for the Use of Unattended Portable Monitors in the Diagnosis of Obstructive Sleep Apnea in Adult Patients. Portable Monitoring Task Force of the American Academy of Sleep Medicine. J. Clin. Sleep Med. 2007, 3, 737-747.

29. Berry, R.B.; Budhiraja, R.; Gottlieb, D.J.; Gozal, D.; Iber, C.; Kapur, V.K.; Marcus, C.L.; Mehra, R.; Parthasarathy, S.; Quan, S.F.; et al. Rules for Scoring Respiratory Events in Sleep: Update of the 2007 AASM Manual for the Scoring of Sleep and Associated Events. J. Clin. Sleep Med. 2012, 8, 597-619. [CrossRef]

30. Burlon, G.; Tepedino, M.; Laurenziello, M.; Troiano, G.; Cassano, M.; Romano, L.; Rinaldi, R.; Ciavarella, D. Evaluation of factors that influence the success rate of OSA treatment with a customised adjustable MAD device-A retrospective study. Acta Otorhinolaryngol. Ital. 2020, 40, 1-7. [CrossRef]

31. Rakel, R.E. Clinical and Societal Consequences of Obstructive Sleep Apnea and Excessive Daytime Sleepiness. Postgrad. Med. 2009, 121, 86-95. [CrossRef] 
32. Tobaldini, E.; Costantino, G.; Solbiati, M.; Cogliati, C.; Kara, T.; Nobili, L.; Montano, N. Sleep, sleep deprivation, autonomic nervous system and cardiovascular diseases. Neurosci. Biobehav. Rev. 2017, 74, 321-329. [CrossRef] [PubMed]

33. Caples, D.S.M.; Rowley, J.A.; Prinsell, D.J.R.; Pallanch, J.F.; Elamin, M.M.B.; Katz, D.S.G.; Harwick, J.D. Surgical Modifications of the Upper Airway for Obstructive Sleep Apnea in Adults: A Systematic Review and Meta-Analysis. Sleep 2010, 33, 1396-1407. [CrossRef] [PubMed]

34. Qian, Y.; Zou, J.; Xu, H.; Zhu, H.; Meng, L.; Liu, S.; Yi, H.; Guan, J.; Yin, S. Association of upper airway surgery and improved cardiovascular biomarkers and risk in OSA. Laryngoscope 2019, 130, 818-824. [CrossRef] [PubMed]

35. Jolanta, K.-J.; Śliwiński, P.; Wojda, M.; Rolski, D.; Mierzwińska-Nastalska, E. Mandibular Advancement Appliance for Obstructive Sleep Apnea Treatment. Adv. Exp. Med. Biol. 2016, 944, 63-71. [CrossRef]

36. Farronato, G.; Giannini, L.; Galbiati, G.; Maspero, C. Comparison of the dental and skeletal effects of two different rapid palatal expansion appliances for the correction of the maxillary asymmetric transverse discrepancies. Miner. Stomatol. 2012, 61, 45-55.

37. Abate, A.; Cavagnetto, D.; Fama, A.; Matarese, M.; Lucarelli, D.; Assandri, F. Short term effects of rapid maxillary expansion on breathing function assessed with spirometry: A case-control study. Saudi Dent. J. 2020, 1-8. [CrossRef]

38. Maspero, C.; Cavagnetto, D.; Abate, A.; Cressoni, P.; Farronato, M. Effects on the Facial Growth of Rapid Palatal Expansion in Growing Patients Affected by Juvenile Idiopathic Arthritis with Monolateral Involvement of the Temporomandibular Joints: A Case-Control Study on Posteroanterior and Lateral Cephalograms. J. Clin. Med. 2020, 9, 1159. [CrossRef]

39. Glos, M.; Penzel, T.; Schoebel, C.; Nitzsche, G.-R.; Zimmermann, S.; Rudolph, C.; Blau, A.; Baumann, G.; Jost-Brinkmann, P.-G.; Rautengarten, S.; et al. Comparison of effects of OSA treatment by MAD and by CPAP on cardiac autonomic function during daytime. Sleep Breath. 2016, 20, 635-646. [CrossRef]

40. De Vries, G.E.; Wijkstra, P.J.; Houwerzijl, E.J.; Kerstjens, H.A.; Hoekema, A. Cardiovascular effects of oral appliance therapy in obstructive sleep apnea: A systematic review and meta-analysis. Sleep Med. Rev. 2018, 40, 55-68. [CrossRef]

41. Perret-Guillaume, C.; Joly, L.; Benetos, A. Heart Rate as a Risk Factor for Cardiovascular Disease. Prog. Cardiovasc. Dis. 2009, 52, 6-10. [CrossRef] [PubMed]

42. Tjugen, T.B.; Flaa, A.; Kjeldsen, S.E. The Prognostic Significance of Heart Rate for Cardiovascular Disease and Hypertension. Curr. Hypertens. Rep. 2010, 12, 162-169. [CrossRef] [PubMed]

43. Makita, S.; Onoda, T.; Ohsawa, M.; Tanno, K.; Tanaka, F.; Omama, S.; Yoshida, Y.; Ishibashi, Y.; Itai, K.; Sakata, K.; et al. Bradycardia is associated with future cardiovascular diseases and death in men from the general population. Atherosclerosis 2014, 236, 116-120. [CrossRef] [PubMed]

Publisher's Note: MDPI stays neutral with regard to jurisdictional claims in published maps and institutional affiliations.

(C) 2020 by the authors. Licensee MDPI, Basel, Switzerland. This article is an open access article distributed under the terms and conditions of the Creative Commons Attribution (CC BY) license (http://creativecommons.org/licenses/by/4.0/). 